\title{
Implementation of Retro-Futurism Style in Architectural Building Design for 3D Animation
}

\author{
SAUD AMERROUF SIAN ${ }^{1} \&$ TERRY LUCAS ${ }^{2}$
}

Faculty of Applied \& Creative Arts, Universiti Malaysia Sarawak, 94300 Kota Samarahan, Sarawak, Malaysia. *Corresponding authors: lterry@unimas.my, saud.sian18@gmail.com

\begin{abstract}
When we heard Retro design, people will think about the fashion, music, poster, style and trend of the 1940s to1980s. The trend retro-futurism, however, is entirely different. It is a trend that was created by writers, artists and film directors in the past and is closely related to science fiction. This research concentrates on investigating the characteristics of retro-futurism and how it can be used to incorporate its features into building design for 3D animation. An exploratory method was used to analyse the architectural design of the past. The gathered information could give some insights and understanding of what retro-futurism is and the reason behind why the architectural design in the previous era was created that way. The process and challenges of implementing retrofuturism visual style are also discussed. As the result of the collected data, developing a design with the aesthetic of retro-futurism become more accessible and well-planned.
\end{abstract}

Keyword: Animation, Retro-futurism, 3D modelling, Art movement, Art period, Exploratory method

Copyright: This is an open-access article distributed under the terms of the CC-BY-NC-SA (Creative Commons attribution non-commercialShareAlike 4.0 International License) which permits unrestricted use, distribution, and reproduction in any medium, for non-commercial purposes, provided the original work of the author(s) is properly cited.

\section{INTRODUCTION}

Building unique and creative structures is an artistic process. In looking for examples from real life, one can draw inspiration from the remarkable view of Shanghai's Pudong district (Whitworth, 2013) and the colossal Dubai's Burj Khalifa (Pamglobe, 2015). These buildings are usually based on artists' vision of the future. Despite the buildings look futuristic, a sense of nostalgia may arise when these magnificent structures are observed because these structures encapsulate significant cultural identity in their design. These experiences can be attributed to the application of retro-futuristic style in the architectural design of those buildings. Retro-futurism is a trend of design and closely related to science and technology, the future as portrayed by the artists, writers and filmmaker of the past. Common depictions of the retro-futuristic world are flying cars, a robot as a butler or an assistant and the architecture design become massive and tall connected by road hanging between the buildings. Although the name is 'retro', it is not firmly dichotomised in a certain era of our history because retro-futurism does not even have a specific timeline. Therefore, the retro-futurism is also associated with the alternate timeline, meaning a world that is different than what we see today.

In the literature, retro-futurism is discussed as the 'past visions of the future' (Coyle \& Mesker, 2013) or 'utopian nostalgia' (Grönholm, 2015). Utopian nostalgia is thought as both reflective and restorative in which the feeling of "personal sensation of loss and longing towards a certain place or time" (Boym, 1996; Grönholm, 2015, p. 375). For instance, this form of retro-futuristic style is commonly seen in the steampunk design concept. The steampunk concept ala Victorian science fiction is commonly regarded as a form or branch of retro-futurism (Guffey, 2014). According to Guffey (2014), steampunk is inspired from the industrial steam engine era with a twenty-first-century twist. Therefore, Guffey (2014) prefers to define retro-futurism as "half-nostalgic, half-sentimental memorialising of popular futurism" (p. 254).

One can draw the exemplars of retro-futurism from several animations such as Thunderbirds, Futurama, and The Jetsons (Anderson, 1964; Groening, 1999; Hanna \& Barbera, 1962) with The Fifth Element, Metropolis, Blade Runner, and The Matrix (Besson, 1997; Lang, 1927; Scott, 1982; Wachowski \& Wachowski, 1999). In these science fiction animation and films, the visual imagery portrayed are of mechanised and robotised society in which people are dependent on automation for leisure and work. The use of digital screens, neon lights, UFO-like skyscrapers, ray guns, and jetpacks as backdrops are quite familiar in these films (Graham, 2016; Sharp, 2011). To add, Syd Mead, the concept artist for the film Blade Runner, drew inspiration from cities like New York City and Chicago with futuristic grid- and linear-like public transportation (Sisson, 2015). The Jetsons (1962) can be viewed as a retro-futuristic themed cartoon, combining space-age era and domestic life, that is imagined from the 1960s 
(Coyle \& Mesker, 2013). Besides the visual style of the animation, The Jetsons experimented with combinations of tune to create the space-age sounds such as synthetic beeping, thuds, whacks, zips, and crashes, and up-tempo jazz to create the retro-futuristic experience (Coyle \& Mesker, 2013). When compared to the present form of technology, Coyle and Mesker (2013) pointed out that the sounds used in The Jetsons animation series were more mechanical than digital. In another example, an attempt to utilise the concept of retro-futurism in a television show is from the Star Trek: Enterprise (2001). The television show's opening title sequence incorporated retro-futurism by utilising images of real technologies from the past and juxtaposed it with the futuristic Star Trek motherships rendered in computer generated graphics (Sharp, 2011). Compendiously, the concept of retro-futurism can be associated with visual and sonic aspects. These aspects have familiar congruence: the accompaniment of technological devices, features, and interface design.

The objectives of this study are to investigate and analyse the example of retro-futurism style and identify its characteristics that are suitable to be incorporated into the architectural design for 3D animation. Much visual representation of the existing artwork or project needs to be studied to fully understand the look and feel of retrofuturism style and its features. These characteristics will be explored and determined which data is relevant to creating building design with retro-futuristic style. Therefore, the study tries to answer these research questions:

1. What are the architectural features that parallel retro-futurism?

2. How to apply the retro-futuristic features in creating computer-generated buildings in animation?

\section{MATERIALS AND METHODS}

Exploratory research is a process of investigating and finding further insight into the subject matter. Elle (2016) explained that the exploratory research is used to acquire a vast collection of data. However, Elle (2016) also mentioned that this research method does not provide a straight answer to the research question, but instead gives a further understanding of the research problem and suggest a potential solution. Since retro-futurism is a trend that tends to change in its design, an exploratory approach is suitable to be utilised in this study due to its flexibility and adaptability to change as new information gathered throughout the study. This method is used to identify different influences of the future past and incorporating with the architecture design in $3 \mathrm{~d}$ software. The primary data include architecture from the past, conceptual building design by architect, painting or illustration, references for movies and TV series. Consequently, the collected data was analysed, recorded and summarised in Table 1, Table 2, and Table 3. Based on the analysis, a conceptual framework for creating a retro-futuristic look. From this retro-futuristic mind map (refer to Figure 1), the researchers design and develop several $3 \mathrm{~d}$ model concepts to be used in a computer animation project.

The retro-futuristic architectural buildings were developed using Autodesk Maya 2018. The process begins with three main phases: (i) pre-production; (ii) production; and (iii) post-production. In the pre-production process, visuals were collected as references. The choice of visuals was guided by the proposed conceptual design of the retro-futuristic style. Thereafter, several sketches were developed to flesh out some potential design. Then, the project members discussed and decided on the choice for the $3 \mathrm{~d}$ structures to be used in the animation. The Production phase began as the choice of retro-futuristic building design has been made. In the production phase, $3 \mathrm{~d}$ models were build based on the finalised sketch. Materials and textures were gathered and filtered to be used for the $3 \mathrm{~d}$ retro-futuristic building design. Once the construction of the $3 \mathrm{~d}$ models was complete, these materials and textures were applied to them. The third phase is the post-production phase. In this phase, the lighting and renderings are adjusted and exported to Adobe After Effects for compositing and editing. The final output is the Final Year Project animation called "Misi Zero". Succinctly, the animation is about a tale of an investigation mission that unexpectedly turns into a rescue mission. Due to the turn of event, the main protagonist, Jo-one must be rescued by Rex from a menacing giant robot threat named Zero. Fellow investigator Rex, who is a robot tried to rescue Jo-one, but Zero was too overpowering. In the effort to defeat Zero, Jo-one, with the help of Terra, an artificial intelligent digital agent, manages to activate a new power for Rex to defeat Zero successfully.

\section{RESULTS \& DISCUSSION}

This research aims to understand what retro-futurism is and how to apply it in architectural design. With the information collected from the primary data, each basic structure and features of the building were listed in tables and figures to have proper structure information and ready to be further analysed. From Table 1, the possible data that can be used to create retro-futurism style building is the architecture from the $19^{\text {th }}$ century as it fits with one of the characteristics of retro-futurism: technology. 
Table 1. A summary of characteristics and essential shape of the architecture based on art period.

\begin{tabular}{|c|c|c|c|}
\hline Art Period & Shape & Feature & Function \\
\hline Egypt & pyramid, rectangular & $\begin{array}{l}\text { monument, column, obelisk, } \\
\text { tomb }\end{array}$ & $\begin{array}{l}\text { store deceased pharaoh and } \\
\text { queen }\end{array}$ \\
\hline Classical & rectangle, semi-sphere & $\begin{array}{l}\text { use column, arches, stone } \\
\text { sculpt }\end{array}$ & place of worship \\
\hline Byzantine & $\begin{array}{l}\text { rectangle, semi-sphere, } \\
\text { octogen }\end{array}$ & $\begin{array}{l}\text { use column, mosaic, } \\
\text { pendentive, dome and arches }\end{array}$ & gathering place for prayer \\
\hline Gothic & $\begin{array}{l}\text { rectangle, thinner than } \\
\text { Byzantine }\end{array}$ & $\begin{array}{l}\text { use flying buttress, pointed } \\
\text { arches, stone statue and } \\
\text { heavily ornate, tall }\end{array}$ & gathering place for prayer \\
\hline Renaissance & rectangle & $\begin{array}{l}\text { use rounded arches, column, } \\
\text { pediments, Stone sculpt }\end{array}$ & $\begin{array}{l}\text { an important building, wealthy } \\
\text { house }\end{array}$ \\
\hline Neoclassicism & $\begin{array}{l}\text { rectangle, semi sphere, } \\
\text { square }\end{array}$ & use column, pediment & $\begin{array}{l}\text { important monument, } \\
\text { administration etc. }\end{array}$ \\
\hline 19th Century & rectangle, square & $\begin{array}{l}\text { use steel structure, many } \\
\text { windows, glass, iron, tall }\end{array}$ & $\begin{array}{l}\text { the official building, support } \\
\text { people to live or work }\end{array}$ \\
\hline
\end{tabular}

Table 2. A summary of the characteristic of the art movement.

\begin{tabular}{cc}
\hline Art Movement & Characteristics \\
\hline Art Nouveau & Colourful, floral ornamentation \\
Art Deco & Symmetrical geometry \\
Bauhaus & Mass production, reject ornamentation, simple \\
\hline
\end{tabular}

Table 2 is the result of investigating the art movement of the past. It has become the main inspiration for designing the building. Art Deco and Bauhaus seems to be the most suitable data to be explored more and apply it in the $3 \mathrm{~d}$ design.

Table 3. Retro-futurism according to different creator based on the primary data.

\begin{tabular}{|c|c|c|}
\hline Creator & Purpose of Design & Applicable in Real Life \\
\hline Architect and Engineer & Aim to be able to function & Possible \\
\hline Artist and Designer & Exploring the visual style (retro-futurism) & No \\
\hline Filmmaker and Animator & $\begin{array}{l}\text { Pleasing to look at / Appealing to the } \\
\text { audience }\end{array}$ & $\begin{array}{l}\text { Design from the movie is } \\
\text { plausible }\end{array}$ \\
\hline
\end{tabular}

Table 3 shows the summary of the research based on three different group of creators. Architect and engineer design their building to be able to function and trying to incorporate create what the new look of future the 
architecture is. Artist and designer create their illustration to explore the genre of retro-futurism, giving their design a unique look and fresh during their time. Filmmaker and animator focus on the look and feel of their design to create an immersive environment for the audience. The design does not have to be functional. However, some concept art from the movie is plausible to be functional because most of the concept artist was an industrial designer and they made detail sketches with the description of why it was designed that way.

By analysing the data above, a mind map is created to find the answer to the research question which identifies characteristics of retro-futurism and how to implement it into $3 \mathrm{~d}$ animation.

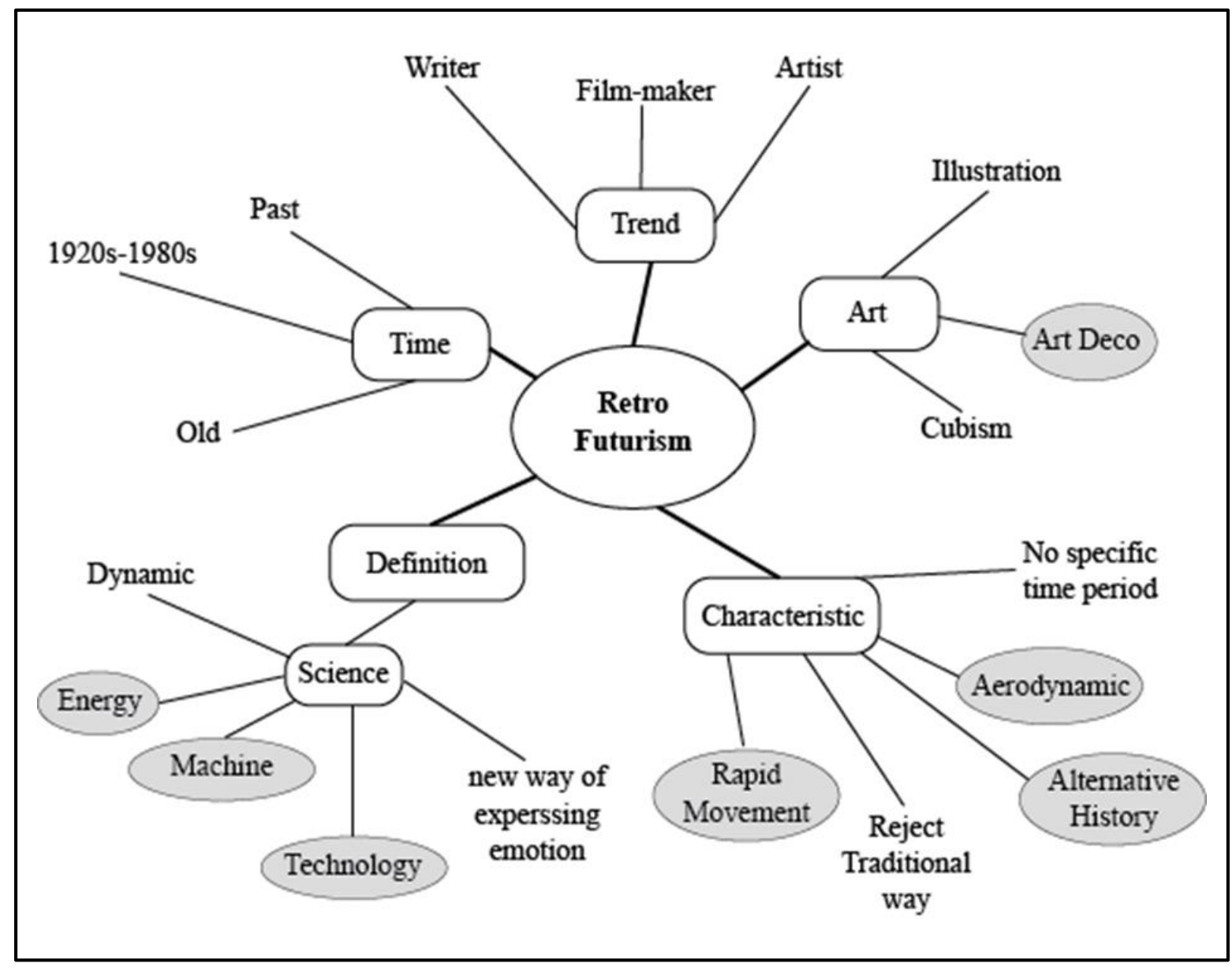

Figure 1. A mindmap of retro-futurism based on the primary data.

The coloured-circle is selected as the most likely data to be used as a guide to developing architecture design. As a result, the researchers drafted a conceptual design of the building based on these selected data. After the data is narrowed down, the process and development of the architecture design can begin. It has three main phase which is pre-production, production and post-production including a few steps until the final product is complete.

\section{I) Pre-Production Phase}

Step One: The primary data are compiled and analysed. The $19^{\text {th }}$ century building design and the illustration of retro-futurism were selected as the primary data as shown in Figure 1. 


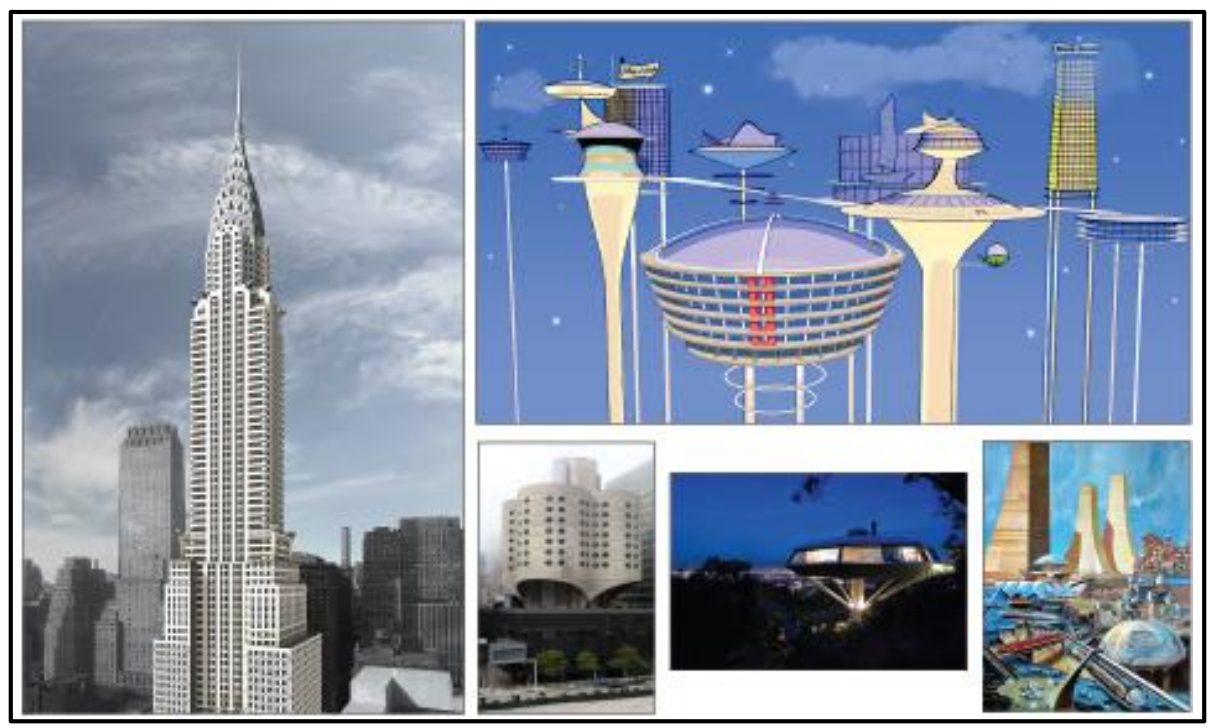

Figure 2. The $19^{\text {th }}$ century building, conceptual building and illustration were used as a reference for the research.

Step Two: Sketches were made to create building designs with an aesthetic of retro-futurism which is shown in Figure 2.

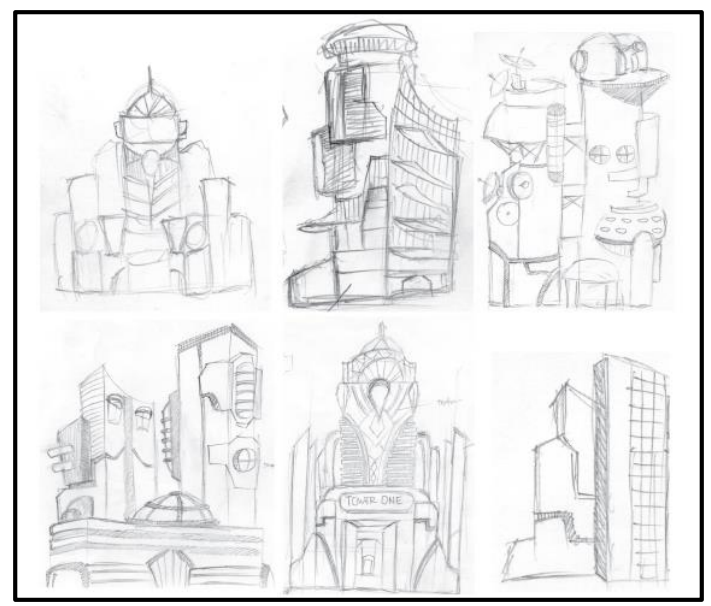

Figure 3. Different sketches of the building.

Step three: From the sketches in Figure 3, the best representation of a building with retro-futurism style is selected for further process. Some of the chosen sketches are shown in Figure 4.

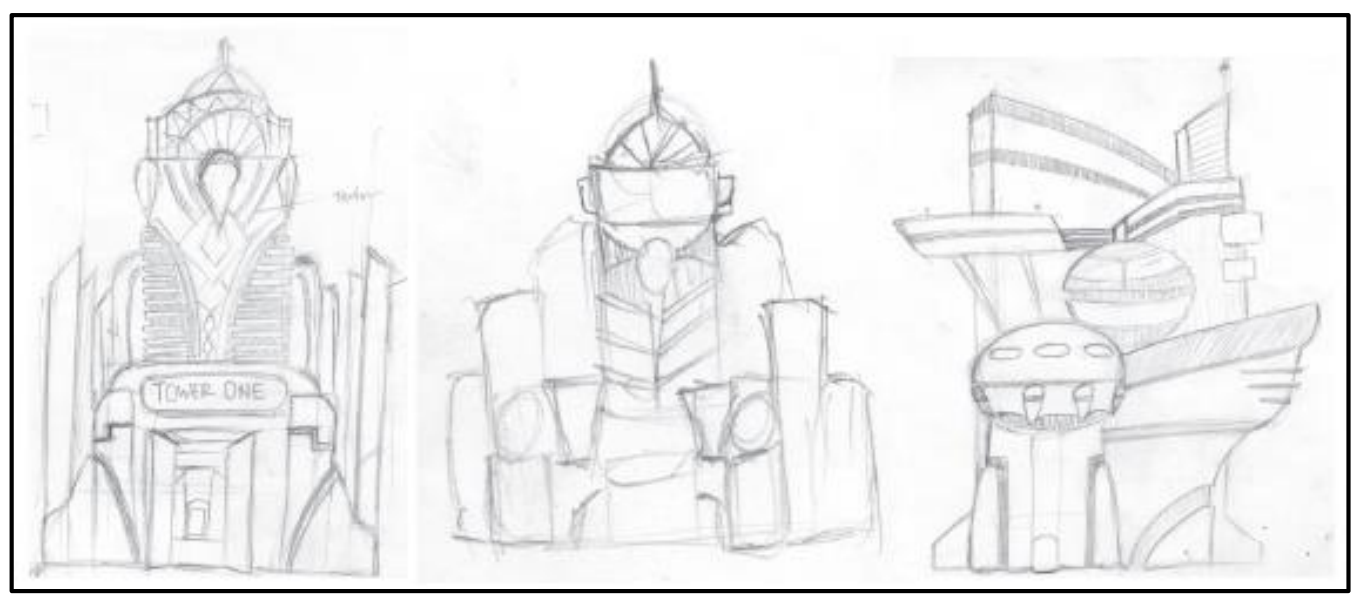

Figure 4. Sketches to be used to model in Autodesk Maya 2018. 
Step four: The selected sketches are then imported into the Autodesk Maya 2018 to be modelled as shown in Figure 5 below.

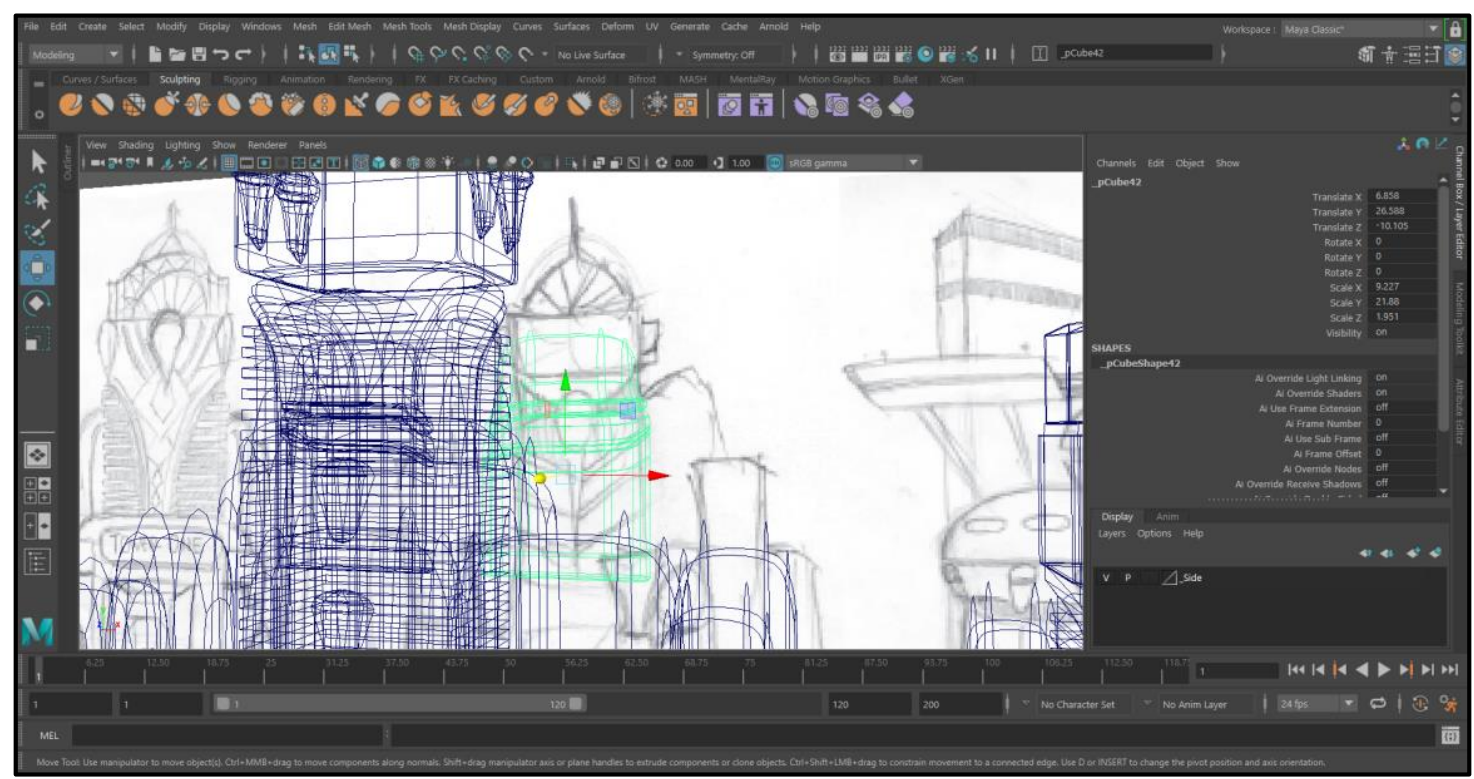

Figure 5. Chosen sketches were modelled in Autodesk Maya 2018.

\section{II) Production Phase}

Step five: After the model is complete, the element of retro-futurism is added to the building. Figure 6 sharper edges use to give the feel of a $19^{\text {th }}$ century building design. The rounded or curvy part of the building is to represent the aerodynamic shape of retro-futurism.

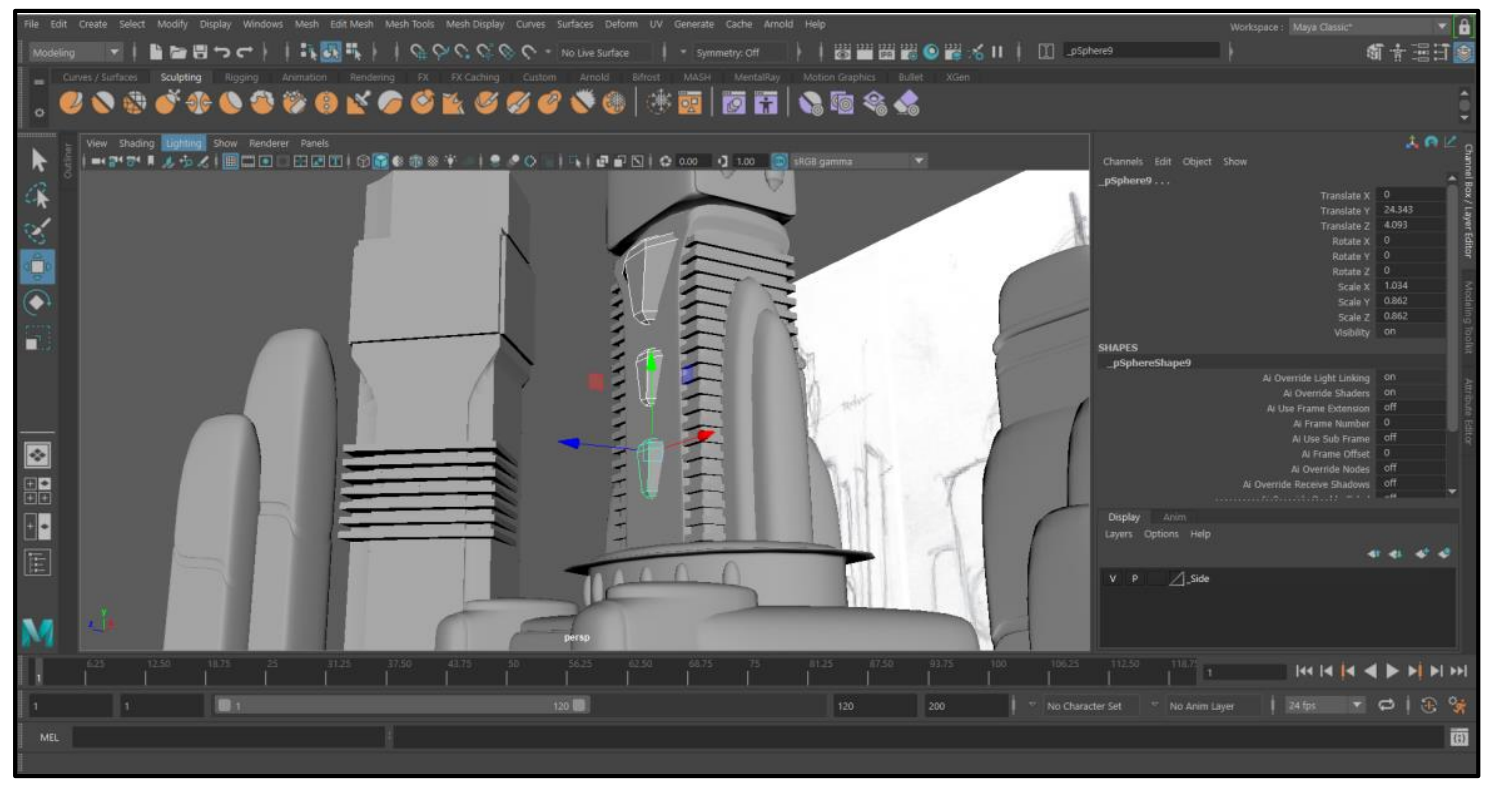

Figure 6. Adding features of retro-futurism in the building design.

\section{III) Post-Production Phase}

Step six: After step 5 is finished, the colour of the building and lighting is added. The setting of the morning, sunset or sunrise and night-time are shown in Figure 7. 


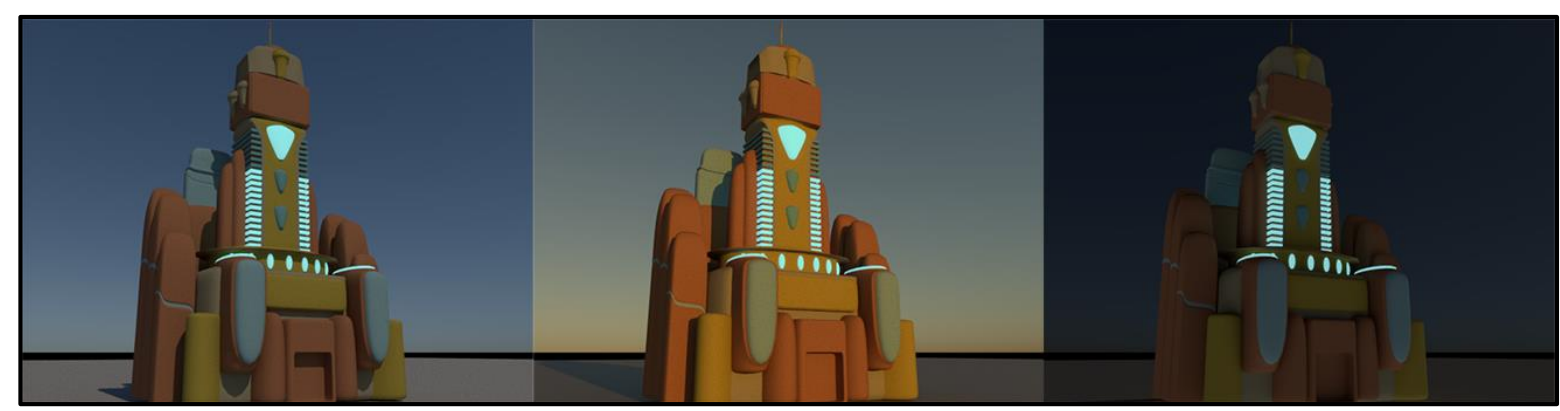

Figure 7. Different sets of lighting in Maya 2018.

Step seven: With step six is complete; the building design is ready to be used and place on the scene of the animation "Misi Zero" (refer to Figure 8).

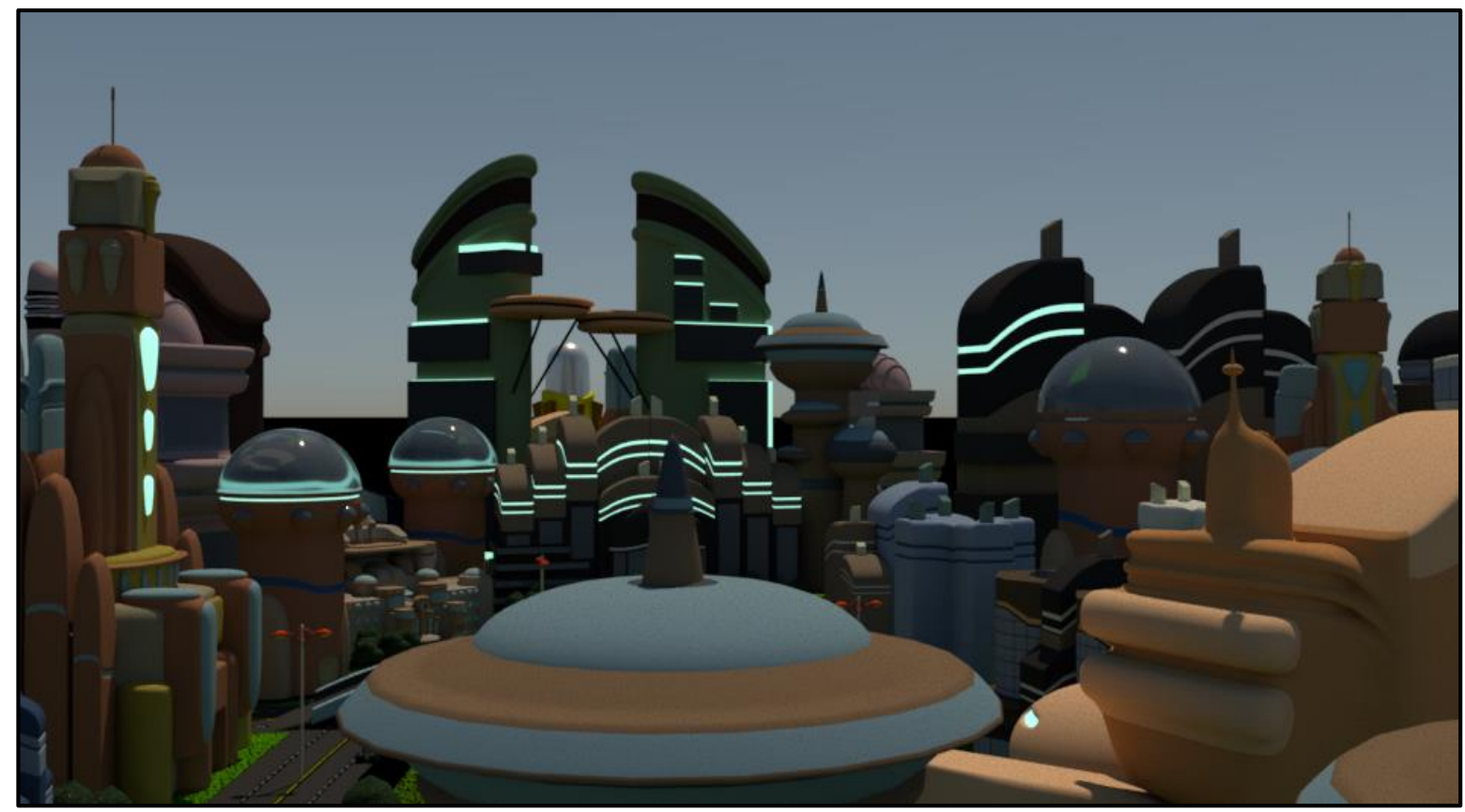

Figure 8. Retro-futuristic buildings appear as the background of the animation "Misi Zero".

This study focuses on identifying significant retro-futuristic characteristics that can be applied in the design and developing $3 \mathrm{~d}$ architectural structures. The collected data have been analysed and investigate to find the solution for the research problem of this study via of exploratory method. From the analysis, a conceptual retro-futuristic design for $3 \mathrm{~d}$ building models is proposed. Moreover, the study also describes the process of applying and constructing a retro-futuristic $3 \mathrm{~d}$ buildings.

Notwithstanding, conducting this research came with its technical challenges as well. Several problems were encountered during the whole process. It is advisable for animators to minimise poly count as low as possible without sacrificing the overall look for the $3 \mathrm{~d}$ model. It was found that the lower poly count $3 \mathrm{~d}$ building model was able to be rendered faster when compared to the higher poly count $3 \mathrm{~d}$ building model. If the low poly objects look presentable and have less or none texture distortion, it can still be considered acceptable. Also, the use of multiple light sources would also result in higher render time. Thus, the setting of the lighting rig must be designed and planned thoroughly to make the rendering process faster. Due to the limitation and time constraint of the Final Year Project, decisions were made to use the option with the faster render time. Another obstacle faced during the animation design and development, it is highly encouraged to ensure that team members use the similar version of the $3 \mathrm{~d}$ modelling software due to an older version of the software was unable to read from the newer version of the software. Furthermore, another suggestion is to avoid designing the $3 \mathrm{~d}$ structures or backdrop that could outshine the character. The actions of the characters are supposed to be the highlight of the animation. Too much visual details in the background would cause the audience to focus less and be distracted from the main action (Lucas \& Abd Rahim, 2017). 


\section{CONCLUSION}

This study focuses on the exploration of retro-futurism from various media such as animation, architectures, films, and images. Based on this exploration, a concept of retro-futurism for designing $3 \mathrm{D}$ buildings was proposed. The concept was then applied in the design of an animation final year project entitled 'Misi Zero' in which the retrofuturistic architectural building models were used in the scenes. The outcome of this research has given the researcher some insight in designing architecture design with retro-futurism style with the help of an exploratory method. Retro-futurism is a trend that has broad possibilities. Based on the data collection, many combinations of data could be used to produce retro-futuristic design by referring to the Table 1, Table 2, Table 3, and Figure 1 . This research could be used by all designed as a conceptual design guide for their design and may not be enough for architect and engineer as it lacks mathematical data, measurement and scale, an example of practical blueprint to be used in real life and so on. This study provides some potential design features that can be used to create retrofuturistic building structures for animation, film, games, and virtual reality. Besides that, the design and development process in this study can be used as a brief guide in constructing $3 \mathrm{~d}$ models. For further research, the next objective could be investigating unique and futuristic building design concepts that are adaptable and formidable to specific weather or the environment. In retrospect, retro-futurism is an attractive visual style or concept as it allows the artists to experiment blending arts and culture from the past with their visions of the future.

\section{ACKNOWLEDGEMENTS}

The authors would take this opportunity to express gratitude to Rizqussalam Bin Samsudin, Mohamad Hafizudin Bin Ali, Claraferra Paulus, and all Design Technology lecturers especially lecturers from Animation for their guidance and support.

\section{REFERENCES}

Anderson, G. (1964). Thunderbirds. USA: ITC Entertainment.

Berman, R., \& Braga, B. (2001). Star Trek: Enterprise. USA: Paramount Pictures.

Besson, L. (1997). The Fifth Element. USA: Columbia Pictures.

Boym, S. (1996). Estrangement as a lifestyle: Shklovsky and Brodsky. Poetics Today, 17(4), 511-530. Retrieved from http://www.jstor.org/stable/1773211

Coyle, R., \& Mesker, A. (2013). Time warp: Sonic retro-futurism in The Jetsons. In K. J. Donnelly \& P. Hayward (Eds.), Music in Science Fiction Television: Tuned to the Future (1st ed., pp. 14-32). New York, NY: Routledge. http://doi.org/10.4324/2F9780203076330-10

Elle, R. (2016). How to Conduct Exploratory Research. [Online]. Retrieved May 24, 2018, from https://www.surveygizmo.com/resources/blog/how-to-conduct-exploratory-research/

Graham, S. (2016). Vertical noir: Histories of the future in urban science fiction. City, 20(3), 389-406. http://doi.org/10.1080/13604813.2016.1170489

Groening, M. (1999). Futurama. USA: 20th Television.

Grönholm, P. (2015). When tomorrow began yesterday: Kraftwerk's nostalgia for the past futures. Popular Music and Society, 38(3), 372-388. http://doi.org/10.1080/03007766.2014.969034

Guffey, E. (2014). Crafting yesterday's tomorrows: Retro-futurism, steampunk, and the problem of making in the $\begin{array}{lllll}\text { twenty-first century. Journal of Modern Craft, 7(3), 249-266. } & \end{array}$ http://doi.org/10.2752/174967714X14111311182767

Hanna, W., \& Barbera, J. (1962). The Jetsons. USA: Warner Bros.

Lang, F. (1927). Metropolis. Germany: Ufa.

Lucas, T. \& Abd Rahim, R. (2017). The similarities and nuances of explicit design characteristics of well-received online instructional animations. Animation. 12(1). 80-99. http://doi.org/ 10.1177/1746847717690671

Pamglobe. (2015). 828 meters /Tower Burj Khalifa Dubai. Retrieved July 26, 2018, from https://www.youtube.com/watch?v=_VeWTuxzVAU

Scott, R. (1982). Blade Runner. USA: Warner Bros.

Sharp, S. (2011). Nostalgia for the future: Retrofuturism in Enterprise. Science Fiction Film \& Television, 4(1), 25-40. http://doi.org/10.3828/sfftv.2011.2

Sisson, P. (2015). Meet Syd Mead, the artist who illustrates the future. Retrieved July 26, 2018, from https://www.curbed.com/2015/7/23/9937790/syd-mead-city-architecture-blade-runner-design-future

Wachowski, L., \& Wachowski, L. (1999). The Matrix. USA: Warner Bros.

Whitworth, R. (2013). This is Shanghai. Retrieved July 26, 2018, from https://www.youtube.com/watch?v=b18BJ37hcrA 